\title{
Interrelation between Fluoride Content in Drinking Water and Dental Caries Prevalence Measured with DMF and ICDAS in Senegal
}

\author{
Aidara AW*, Leye-Benoist F, Sarr M, Faye B, Kane AW and Touré B \\ Service of Conservative Dentistry, Department of Odontology, Cheikh Anta Diop University of Dakar, Senegal \\ ${ }^{*}$ Corresponding author: Aidara AW, Service of Conservative Dentistry, Department of Odontology, Cheikh \\ Anta Diop University of Dakar, Dakar, Fann, Senegal 25 286, Tel: +221 3386057 39, 77454 24 55, E-mail: \\ wakha.aidara@ucad.edu.sn, awakha@gmail.com \\ Citation: Aidara AW, Leye-Benoist F, Sarr M, Faye B, Kane AW, et al. (2017) Interrelation between fluoride \\ content in drinking water and dental caries prevalence measured with DMF and ICDAS in Senegal. J Dent \\ Oral Care Med 3(3): 301
}

Received Date: November 20, 2017 Accepted Date: December 27, 2017 Published Date: December 29, 2017

\begin{abstract}
Objective: This study aimed to establish a correlation between the dental caries prevalence measured with the DMFT and ICDAS indexes and the rate of fluorine content in drinking water.

Materials and methods: A national dental caries prevalence data measured with ICDAS and DMFT indexes at several thresholds were correlated with the fluoride content of drinking water in several regions of Senegal. The dental caries prevalence was calculated based, distinctively, on the DMFT and ICDAS criteria. The variation of the rate of fluorine content in the drinking water of different regions was calculated according to the WHO reference rate.

Results: When the DMFT index is used, the dental caries prevalence correlates with the rate of fluor content in drinking water. But, when dental caries prevalence is measured with ICDAS, our results show that the rate of fluorine contained in drinking water does not affect the decayed teeth prevalence.
\end{abstract}

Conclusion: This study has provided with significant information on using DMFT vs ICDAS. It would be shown that a correlation could be made between the degree of dental fluorosis and the dental caries prevalence measured with the ICDAS.

Keywords: Dental Caries; DMFT; Fluorosis; ICDAS

\section{Introduction}

Carious lesions appear when teeth are demineralized/remineralized several times a day and during a relatively long time of demineralization. However, early carious lesions can be stopped or even restored with fluorine which, in dentistry, is used as fluoride [1-5]. Fluoride serves as the caries control by interfering with tooth de/remineralization processes. It decreases mineral loss when it is present in the oral cavity at low and constant concentrations and, therefore, reduces the rate of caries progression [6-10]. However, high intake doses of fluoride during the mineralization of enamel can cause dental fluorosis. At higher levels, there is a risk of bone fluorosis with its consequences on the body. More than 60 years ago, the balance between the anti-caries benefit of fluoride and the risk of dental fluorosis was discussed [5-9]. Dental caries and fluorosis are worldwide public health problems $[2,6,8,10,11]$. There is no cure for fluorosis, prevention is the only treatment available. Many countries have stopped the fluoridation of water supply. So, for a long time, the dental caries prevalence was high (80\%) among educated regardless of the country. The scientific community has never questioned the usefulness or relevance of the DMFT index. In epidemiology, tools were not available to appropriately diagnosis caries cavities until early 2000, when Pitts proposed the ICDAS index, which detects both non-cavity and cavity caries, even in epidemiological surveys [12-15]. Several studies were focused on comparing results of the dental caries prevalence measured with DMFT vs. ICDAS $[12,16,17]$. Aidara's study, which used both methods, reports/shows dental caries prevalence at different thresholds: enamel threshold, dentin and tooth decay with pulpal tint. This study has also provided useful information between the DMFT index and the ICDAS [16]. Several regions of Senegal have high levels of fluoride in their drinking water. According to some authors, $18 \%$ of the population consume hyperfluorinated water, $62 \%$ hypofluorinated water and $20 \%$ norm of fluorinated water, according to WHO standards [18]. The objective of this study was to establish a correlation between the dental caries prevalence measured with DMFT and ICDAS indexes and the rate of fluorine content in the drinking water. It will be to specifically assess whether populations living in areas where the rate of fluoride in 
drinking water compared with WHO's standards has carioprotection on carious lesions.

\section{Materials and Methods}

National dental caries prevalence data measured with the ICDAS and DMFT index at several thresholds were correlated with the fluoride content of drinking water in the following regions: Dakar, Thiès, Louga, Saint-Louis, Fatick and Ziguinchor. The epidemiological survey of Aïdara [16] and the work of Yam [18] in these regions provide with these data.

The variation of the rate of fluorine content in the drinking water of these regions, compared with the WHO reference rate, was calculated using the following formula and presented in Table 1:

$$
\text { reference }=\frac{(T \cdot \max -r e f)}{r e f} * 100
$$

\begin{tabular}{|c|c|}
\hline Region & Reference \\
\hline Dakar & $-67 \%$ \\
\hline Thiès & $-33 \%$ \\
\hline Louga & $33 \%$ \\
\hline Saint-Louis & $0 \%$ \\
\hline Fatick & $>33 \%$ \\
\hline Ziguinchor & $-67 \%$ \\
\hline
\end{tabular}

Table 1: Variation of the fluorine content according to the WHO Reference

The dental caries prevalence was calculated using the DMFT and ICDAS criteria. The data presented in Table 2 were analyzed.

\begin{tabular}{|c|c|}
\hline Codes & Libellés \\
\hline Code 20 & Number of decayed teeth at D3 \\
\hline Code 21 & Number of DMF (decayed. missed. filled) \\
\hline Code 22 & $\begin{array}{l}\text { Existence of untreated carious teeth } \\
\text { reaching dentin } \text { ICDAS }_{4.5 \text { ou } 6}\end{array}$ \\
\hline Code 23 & $\begin{array}{c}\text { Existence of caries cavities }\left(\text { ICDAS }_{5 \text { ou } 6}\right): \\
\text { « yes» }=1 \text { and « no } »=2\end{array}$ \\
\hline Code 24 & $\begin{array}{c}\text { Existence of score } \neq 0 \text { « no carie } »=1 \text { and } \\
\text { " carie ICDAS } \\
\text { caries ICDAS } 4 \text { ICDealthy teeth or } \\
\text { cars }\end{array}$ \\
\hline Code 25 & $\begin{array}{l}\text { Existence of carie ICDAS } \\
{\text { obvious caries } \text { ICDAS }_{5 \text { et } 6}=2}=1 \text { or }\end{array}$ \\
\hline Code 26 & $\begin{array}{c}\text { Number of } 1^{\text {st }} \text { and } 2^{\text {nd }} \text { molars decayed } \\
\mathrm{D}_{1}=\mathrm{M} 1 \text { and } \mathrm{M} 2 \text { at } \mathrm{ICDAS}_{1.2 .3 .4}\end{array}$ \\
\hline Code 27 & $\begin{array}{c}\text { Number of } 1^{\text {st }} \text { and } 2^{\text {nd }} \text { molars decayed } \\
D_{3}=M 1 \text { and } M 2 \text { at ICDAS } \\
5.6\end{array}$ \\
\hline
\end{tabular}

The descriptive analysis focused on the number and the frequency. Data were analyzed according to the level of education or the age (primary school or 12 years old and college or 15 years old), the sex (boy or girl) and the residential area (urban, suburban or rural).

The residential area was coded as follows:

-1: Urban: relative to the city

-2: Suburban: surrounding the city, suburbs

-3: Rural: municipality with less than 2,000 inhabitants

For all codes, 21 to 27, the chi-square test was used for inter-regional data and for comparisons according to the residential area; the binomial law to compare by sex and by the level of education or age. With the Pearson correlation, the link between caries prevalence and fluoride content in drinking water in targeted regions was established. For the whole analysis, the threshold of statistical significance was set at $\mathrm{p} \geq 0.05$.

\section{Results}

\section{Fluorine content in water and dental caries prevalence}

Figure 1 shows the fluoride content in drinking water in areas with assessed caries prevalence. This figure shows that Thiès and Saint-Louis are the only regions with acceptable fluorine content according to WHO standards $(0.7-1.5 \mathrm{mg} / \mathrm{l})$. The drinking water 
of Dakar and Ziguinchor would be hypofluorinated and that of Louga and Fatick hyperfluorinated.

Fluor rate contained in drinking water

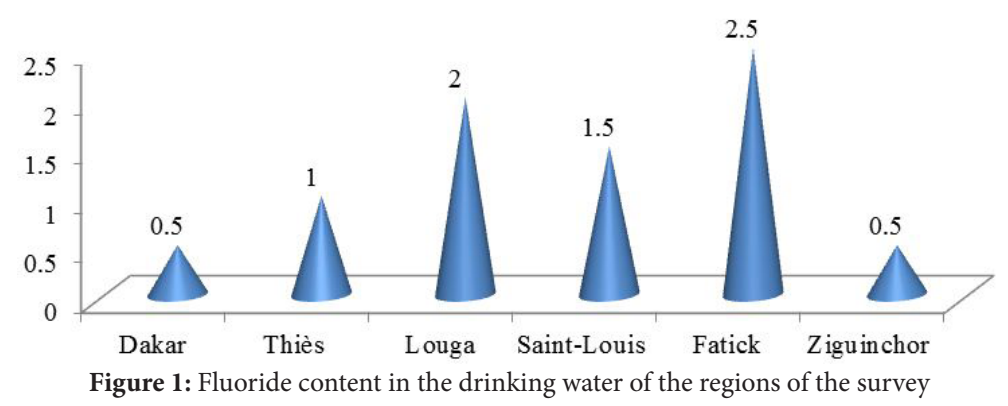

\section{Dental caries prevalence according to DMFT and ICDAS in all regions}

Table 3 shows that, regardless of the code used, the dental caries prevalence is higher in Dakar followed by Saint-Louis and Thiès. Fatick and Ziguinchor have lower rates. However, rates are statistically significant for all codes except code $22(\mathrm{p}=0.23)$ that refers to the existence of untreated decayed teeth reaching the dentin ICDAS ${ }_{4,5 \text { or } 6}$.

\begin{tabular}{|c|c|c|c|c|c|c|c|}
\hline Regions & $\begin{array}{c}\text { Code 21 } \\
(\mathbf{p = 0 . 0 0 1 )}\end{array}$ & $\begin{array}{c}\text { Code 22 } \\
(\mathbf{p}=\mathbf{0 . 2 3 3})\end{array}$ & $\begin{array}{c}\text { Code 23 } \\
(\mathbf{p}=\mathbf{0 . 0 0 1})\end{array}$ & $\begin{array}{c}\text { Code 24 } \\
(\mathbf{p}=\mathbf{0 . 0 0 1})\end{array}$ & $\begin{array}{c}\text { Code 25 } \\
(\mathbf{p}=\mathbf{0 . 0 0 1})\end{array}$ & $\begin{array}{c}\text { Code 26 } \\
(\mathbf{p}=\mathbf{0 . 0 0 1})\end{array}$ & $\begin{array}{c}\text { Code 27 } \\
(\mathbf{p}=\mathbf{0 . 0 0 1})\end{array}$ \\
\hline Dakar & $45.6 \%$ & $44.1 \%$ & $43.6 \%$ & $46.3 \%$ & $47.0 \%$ & $44.5 \%$ & $42.1 \%$ \\
\hline Thiès & $15.0 \%$ & $16.5 \%$ & $15.6 \%$ & $17.8 \%$ & $18.4 \%$ & $17.2 \%$ & $16.7 \%$ \\
\hline Louga & $9.8 \%$ & $10.2 \%$ & $9.6 \%$ & $10.2 \%$ & $9.6 \%$ & $10.2 \%$ & $8.8 \%$ \\
\hline Saint Louis & $18.9 \%$ & $21.1 \%$ & $21.6 \%$ & $15.3 \%$ & $10.4 \%$ & $14.8 \%$ & $22.7 \%$ \\
\hline Fatick & $3.3 \%$ & $3.1 \%$ & $4.8 \%$ & $7.0 \%$ & $10.6 \%$ & $6.7 \%$ & $4.6 \%$ \\
\hline Ziguinchor & $7.4 \%$ & $5.0 \%$ & $4.8 \%$ & $3.4 \%$ & $3.9 \%$ & $6.6 \%$ & $5.1 \%$ \\
\hline Total & $\mathbf{1 0 0 . 0 \%}$ & $\mathbf{1 0 0 . 0 \%}$ & $\mathbf{1 0 0 . 0 \%}$ & $\mathbf{1 0 0 . 0 \%}$ & $\mathbf{1 0 0 . 0 \%}$ & $\mathbf{1 0 0 . 0} \%$ & $\mathbf{1 0 0 . 0 \%}$ \\
\hline
\end{tabular}

Table 3: Dental Caries Prevalence according to DMFT and ICDAS in all Regions

\section{Dental caries prevalence according to ICDAS index only in all regions}

Decayed teeth requiring preventive only and/or interceptive interception are those with obvious caries. Code 24: existence of a score $\neq 0$ "idem of caries" and "caries 1,2, 3 and 4" (healthy teeth or caries ICDAS $_{1,2,3,4}$ that require preventive or interceptive intervention). According to the ICDAS index, only $11.7 \%$ of the population does not show caries. The rest (88.3\%) needs interception or prevention. More than half (57.04\%) of the population have ICDAS $_{1234}$ caries (without the pulpal affected) and the remaining (42.96\%) have advanced caries (with pulpal affected) that require a surgical intervention. Among the teeth which present a cavity ICDAS $_{1,2,3,4}, 47.7 \%$ have the Code 22 or the presence of untreated carious (decayed) teeth reaching the dentin. Data show that $37.04 \%$ of teeth have a cavity of caries visible with the naked eye $\left(\operatorname{ICDAS}_{5,6}\right)$. The rest represents non-cavity carious lesions.

\section{Carious prevalence of permanent molars (M1 and M2)}

Code 26: Number of $1^{\text {st }}$ and $2^{\text {nd }}$ Molar decayed D1 $=M 1$ and $M 2$ to $\operatorname{ICDAS}{ }_{1,2,3,4}$

Code 27: Number of $1^{\text {st }}$ and $2^{\text {nd }}$ Molar decayed D3 $=$ M1 and M2 to ICDAS ${ }_{5,6}$

The decayed molars prevalence, according to regions and according to the age (level of education), is higher in Fatick (78.95\%) for pupils aged 15 years (college) and Thiès (78.33\%) for 12-year-old's (primary school) (Figure 2). The results are statistically significant $(\mathrm{p}=0.001)$. For pupils at the college level (15 years), after Fatick $(78.95 \%)$, Dakar $(61.29 \%)$ and Louga (57.14\%) have the highest prevalence. For primary school (pupils 12 years), after Thiès (78.33\%), Fatick (76.47\%) and Louga (61.76\%) have the highest prevalence.

Data in Table 4 show that the decayed molars prevalence, regardless of age (level of education), is higher in Louga for the stage D1 (code 26), although results are not statistically significant. For 12-year-old pupils, at stage D1 (code 26) after Louga, Thiès (95\%) and Saint-Louis (93.75\%) have the highest rates. For the stage D3 (code 27), data from Saint-Louis (43.75\%) showed highest rates, followed by Dakar (28.65\%) and Louga (23.53\%). The results are not statistically significant.

For 15-year-old pupils, at stage D3 (code 27), after Louga, Thiès (96\%) and Saint-Louis (95.74\%) have the highest rates. Concerning the stage D3 (code 27), data from Saint-Louis (59.57\%) showed the highest rate, followed by Thiès (50\%) and Louga (39.29\%). The results are not statistically significant. 


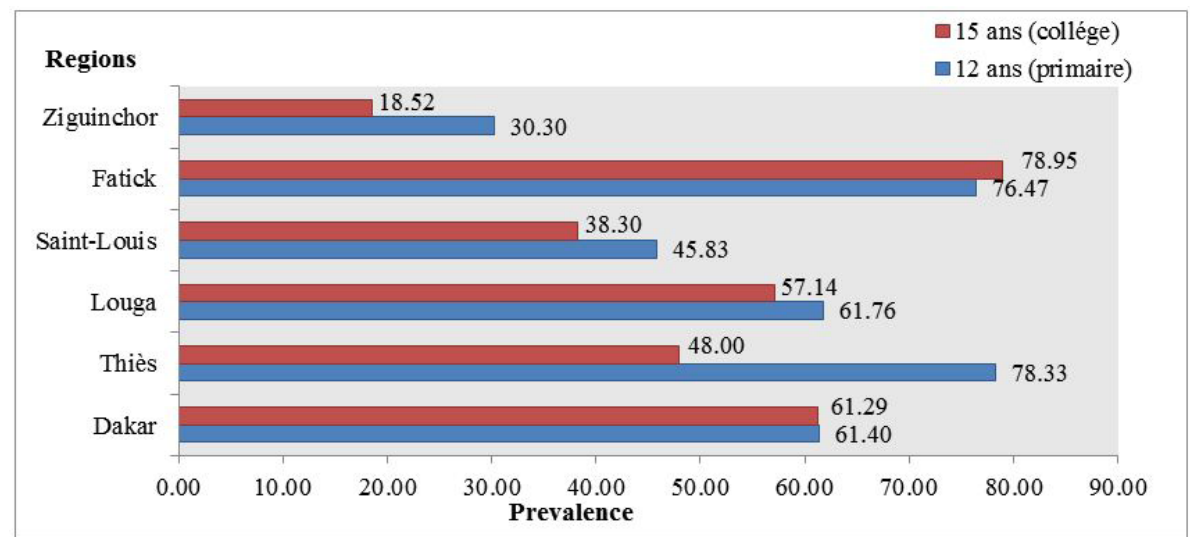

Figure 2: Distribution of the decayed molars prevalence according to the regions and depending on the age (level of education)

\begin{tabular}{|c|c|c|c|c|c|c|c|c|c|c|c|c|}
\hline \multirow[t]{2}{*}{ Age } & \multicolumn{2}{|c|}{$\begin{array}{c}\text { Dakar } \\
(\mathrm{p}=0 \mathbf{0 1 8} / 0.463)\end{array}$} & \multicolumn{2}{|c|}{$\begin{array}{c}\text { Thiès } \\
(\mathrm{p}=0.433 / 0.020)\end{array}$} & \multicolumn{2}{|c|}{$\begin{array}{c}\text { Louga } \\
(\mathrm{p}=0.446 / 0.491)\end{array}$} & \multicolumn{2}{|c|}{$\begin{array}{l}\text { Saint Louis } \\
(\mathrm{p}=1 / 0.317)\end{array}$} & \multicolumn{2}{|c|}{$\begin{array}{c}\text { Fatick } \\
(\mathrm{p}=\mathbf{0 . 0 8 6 / 0 . 2 0 9 )}\end{array}$} & \multicolumn{2}{|c|}{$\begin{array}{l}\text { Ziguinchor } \\
(\mathrm{p}=1 / 0.763)\end{array}$} \\
\hline & code 26 & code 27 & code 26 & code 27 & code 26 & code 27 & code 26 & code 27 & code 26 & code 27 & code 26 & code 27 \\
\hline 12 years & 90.64 & 28.65 & 95.00 & 18.33 & 100 & 23.53 & 93.75 & 43.75 & 76.47 & 20.59 & 60.61 & 18.18 \\
\hline 15 years & 93.55 & 33.87 & 96.00 & 50.00 & 100 & 39.29 & 95.74 & 59.57 & 78.95 & 15.79 & 74.07 & 18.52 \\
\hline
\end{tabular}

Table 4: Number of $1^{\text {st }}$ and $2^{\text {nd }}$ molars decayed prevalence of D1 and D3 for each region according to the age (level of education)

The Pearson correlation applied to the caries prevalence according to ICDAS's and regardless of the carie's severity (code 22, 24, 25 ), and the molars M1 and M2 decayed prevalence at stage D1 and D3 (code 26, 27) with the variation fluorine content compared with the WHO reference in several targeted regions (Table 5), shows that the variation of the fluorine level compared with the WHO reference explains the difference of prevalence by region. Although not very strong, this relationship is more strongly explained for the code $25(r=0.507)$, code $24(r=0.437)$ and code $26(r=0.314)$ than for code $22(r=0.058)$ and code $27(r=$ $0.119)$. The results are not statistically significant for all codes.

\begin{tabular}{|c|c|c|c|c|c|c|c|c|c|c|}
\hline & \multicolumn{2}{|c|}{ Code 22 } & \multicolumn{2}{c|}{ Code 24 } & \multicolumn{2}{c|}{ Code 25 } & \multicolumn{2}{c|}{ Code 26 } & \multicolumn{2}{c|}{ Code 27 } \\
\hline & F rate & $\begin{array}{c}\text { F vs } \\
\text { WHO }\end{array}$ & F rate & $\begin{array}{c}\text { F vs } \\
\text { WHO }\end{array}$ & F rate & $\begin{array}{c}\text { F vs } \\
\text { WHO }\end{array}$ & F rate & $\begin{array}{c}\text { F vs } \\
\text { WHO }\end{array}$ & F rate & $\begin{array}{c}\text { F vs } \\
\text { WHO }\end{array}$ \\
\hline r & -0.115 & 0.058 & 0.352 & 0.437 & 0.576 & 0.507 & 0.167 & 0.314 & -0.017 & 0.119 \\
\hline P-value & 0.828 & 0.913 & 0.494 & 0.386 & 0.232 & 0.305 & 0.752 & 0.544 & 0.974 & 0.822 \\
\hline
\end{tabular}

r: Pearson's correlation

F rate: rate of fluoride content in drinking water

F vs WHO: variation of the fluorine content in drinking water compared to the WHO reference

Table 5: Dental caries prevalence according to ICDAS correlated (Pearson) with the rate of fluoride content in drinking water and with the variation of the fluorine content compared to the WHO reference

When applying the Pearson correlation to the dental caries prevalence according to ICDAS's and regardless of caries' severity (code 22, 24, 25), and the prevalence of molars (M1) and (M2) decayed in stage D1 and D3 (code 26, 27) with the rate of fluoride content in the drinking water of targeted regions (Table 5) shows that the correlation between the rate of fluorine and the caries prevalence in each region is positively related respectively for code $25(\mathrm{r}=0.576)$, code $24(\mathrm{r}=0.352)$ and code $26(\mathrm{r}=0.167)$. It is low and negatively related for code $22(r=-0.115)$ and code $27(r=-.017)$. Results are not statistically significant for all codes.

\section{Discussion}

Senegal is one the countries with hyperfluorinated drinking water in some of its regions. Thus, this study's main objective was to see if the content in fluorine in drinking water in Senegal would have a preventive effect on caries data measured with DMFT and ICDAS indexes of pupils from 12 to 15 years old. Out of this study's targeted regions, only drinking water in Saint-Louis has a fluoride content that is equivalent to WHO standards. In 33\% of regions, the water fluorine content is higher than that recommended by the WHO and in $50 \%$ of visited areas, it met the recommendations. Thus, the results corroborate those of other studies of same theme when the comparison is made with the DMFT index [11,19,20]. When prevalence is measured with ICDAS, results of our study show that the rate of fluorine contained in drinking water does not affect the decayed teeth prevalence. It is higher in Dakar (hypofluoride), Louga (hyperfluoride) and Thies (normofluorea). However, decayed molars are paradoxically more important in Fatick (hyperfluoride). This high caries molars prevalence in an area with high fluorine content in the water is surprising and raises a question of research to determine the reasons. The results of Ramezine's study [20] with the DMFT showed a significant link between the level of fluorine and caries in four out of five provinces. The study of Bergamo in Brazil [19], which focused on the benefit/risk of caries and fluorosis balance, but did not measure the carious' severity, showed a high percentage of 
samples with insignificant advantage $(<0.45 \mathrm{mg} \mathrm{F} / \mathrm{L}$ and higher risk ( $>1.14 \mathrm{mg} \mathrm{F} / \mathrm{L})$ [19]. The prospective study of Yeung [11] on the prevention of dental caries with fluoridated milk showed that consuming milk for three years reduces the decay of permanent and primary teeth. The DMFT/dmft index was used to measure the degree of carious effect. For primary teeth, the reduction was substantial (31\%) while for permanent teeth, the degree of caries was very low [11].

One of this study's boundaries is that the population's teeth fluorosis severity was not known, while Ramezani's multicentric study in Iran [20], where areas of hyperfluorosis were also noted, has focused on the effect of fluoride concentration in water on dental caries and fluorosis measured with Dean's index. However, in the Ramezani study, dental caries were measured only with the DMFT index while our study has used both indexes (DMFT and ICDAS). The correlation between the fluoride rate and the dental caries prevalence measured with the ICDAS index in each region of Senegal is positively related for the existence of ICDAS caries $1,2,3$ and $4=1$ caries or of obvious caries ICDAS $_{5,6}=2(\mathrm{r}=0.576)$, the existence of a score $\neq 0$ "idem caries" $=1$ and "caries $\operatorname{ICDAS}_{1,2,3,4} "=2$ (healthy teeth or caries $\left.\operatorname{ICDAS}_{1234}\right)(\mathrm{r}=0.352)$ and the number of $1^{\text {st }}$ and $2^{\text {nd }}$ molars decayed D1 $=$ M1 and M2 to $\operatorname{ICDAS}_{1,2,3,4}(\mathrm{r}=0.167)$.

Our methodology makes the difference with other studies mentioned above [11,19,20]. The works of Ramezani (2015) and Yeung (2015) used the DMFT index, which is now considered as an index that hides caries that do not require invasive treatment and hides inequalities - the total number of caries and their degree of severity - within a population but also in the same individual $[11,20]$. While the ICDAS index used in our study, besides being able to detect carious lesions from the first changes in enamel tissue to pulpal affect, can differentiate a beginning dental fluorosis from caries from enamel by visual changes enamel staining of the type "white spot" and "brown spot", which could be erroneously considered as fluorosis.

When analyzing the effect of drinking-water consumption on the first and second molars decayed prevalence with the DMFT index (at the stage D1 and D3), our results show that the variation of the fluorine content of targeted regions compared with the WHO reference explains the difference in prevalence in each of these regions. An adequate concentration of Fluor in drinking water would be required for fluoridation of the water to achieve caries prevention goals with minimal risk of fluorosis. Similarly, concerning the fluorosis, several days of exposure to high levels of fluoride during enamel formation are required for visible or clinically detectable changes.

\section{Conclusion}

It would be indicated that a correlation could be made between the degree of dental fluorosis in the survey population measured with the Index CFI or the "Tooth Surface Index of Fluorosis" (TSIF) and the dental prevalence with the ICDAS. The TSIF is an index equivalent at ICDAS because the dental fluorosis is searched in all dental surfaces, as caries with the ICDAS index. In addition, monitoring the fluoride concentration in various sources, may help to establish appropriate preventive measures. It would indicate the implementation of a national program for the implementation of preventive and/or interceptic measures for permanent molars in all regions of Senegal. It is specifically urgent to plan campaigns for the prevention of caries of tooth decay and backup of permanent molars by sealing pits and fissures of these permanent molars, even in hyperfluorinated areas.

\section{References}

1. Featherstone JD (2009) Remineralization, the natural caries repair process the need for new approaches. Adv Dent Res 21: 4-7.

2. Scottish Intercollegiate Guidelines Network (2014) Dental interventions to prevent caries in children: a national clinical guideline, Scotland.

3. ten Cate JM, Fetherstone JD (1991) Mechanistic aspects of the interactions between fluoride and dental enamel. Crit Rev Oral Biol Med 2: 283-96.

4. Fejerskov O, Thylstrup A, Larsen MJ (1981) Rational use of fluorides in caries prevention. A concept based on possible cariostatic mechanisms. Acta Odontol Scand 39: 241-9.

5. Santos Lde M, Reis JI, Medeiros MP, Ramos SM, Araújo JM (2009) In vitro evaluation of fluoride products in the development of carious lesions in deciduous teeth. Braz Oral Res 23: 296-301.

6. European Archives of Padiatric Dentistry (2009) Guidelines on the use of fluoride in children: an EAPD policy document. Eur Arch Paediatr Dent 10: 129-35.

7. Lee YE, Baek HJ, Choi YH, Jeong SH, Park YD, et al. (2010) Comparison of remineralization effect of three topical fluoride regimens on enamel initial carious lesions. J Dent 38: 166-71.

8. Iheozor-Ejiofor Z, Worthington HV, Walsh T, O'Malley L, Clarkson JE, et al. (2015) Water fluoridation for the prevention of dental caries. Cochrane Database Syst Rev 18: 10.1002/14651858.CD010856.pub2.

9. Amaechi BT, van Loveren C (2013) Fluorides and non- fluoride remineralization systems. Monogr Oral Sci 23: 15-26.

10. Featherstone JD, White JM, Hoover CL, Rapozo-Hilo M, Weintraub JA, et al. (2012) A randomized clinical trial of anticaries therapies targeted according to risk assessment. Caries Res 46: 118-29.

11. Yeung CA, Hitchings JL, Macfarlane TV, Threlfall AG, Tickle M, et al. (2015) Fluoridated milk for preventing dental caries. Cochrane Database Syst Rev 18: CD003876.

12. Aidara AW, Pitts N, Ottolenghi L, Senakola E, Bourgeois D (2016) Comparison between measurements of tooth decay with an International Caries Detection and Assessment System method versus the decayed, missing and filled teeth method. Int J Contemp Dent 7: 1-9.

13. Shivakumar KM, Prasad S, Chandu GN (2009) International Caries Detection and Assessment System. A new paradigm in detection of dental caries. J Conserv Dent 12: 10-6

14. Pitts N (2004) "ICDAS"--an international system for caries detection and assessment being developed to facilitate caries epidemiology, research and appropriate clinical management. Community Dent Health 21: 193-8. 
15. Ismail AI, Sohn W, Tellez M, Amaya A, Sen A, et al. (2007) The International Caries Detection and Assessment System (ICDAS): an integrated system for measuring dental caries. Community Dent Oral Epidemiol 35: 170-8.

16. Aïdara AW, Bourgeois D (2014) Prevalence of tooth decay: a national pilot study comparing the decay severity index (CAO) vs ICDAS in Senegal [Prévalence de la carie dentaire : étude pilote nationale comparant l'indice de sévérité de la carie (DMFT) vs ICDAS au Sénégal]. Odonto -Stomatologie Tropicale 37: 53-63.

17. Melgar RA, Pereira JT, Luz PB, Hugo FN, Araujo FB (2016) Differential Impacts of Caries Classification in Children and Adults:A Comparison of ICDAS and DMF-T. Braz Dent J 27: 761-6.

18. Yam AA (1995) Détermination de la dose optimale de fluor dans l'eau de boisson au Sénégal in: Techniques. sciences. méthodes: TMS; la revue mensuelle des spécialistes de l'environnement (Paris : ASTEE) No. 6, France.

19. Bergamo ET, Barbana M, Terada RS, Cury JA, Fujimaki M (2015) Fluoride concentrations in the water of Maringá. Brazil. considering the benefit/risk balance of caries and fluorosis. Braz Oral Res 29: 47.

20. Ramezani G, Valaie N, Rakhshan V (2015) The effect of water fluoride concentration on dental caries and fluorosis in five Iran provinces: A multi-center twophase study. Dent Res J (Isfahan) 12: 31-7.

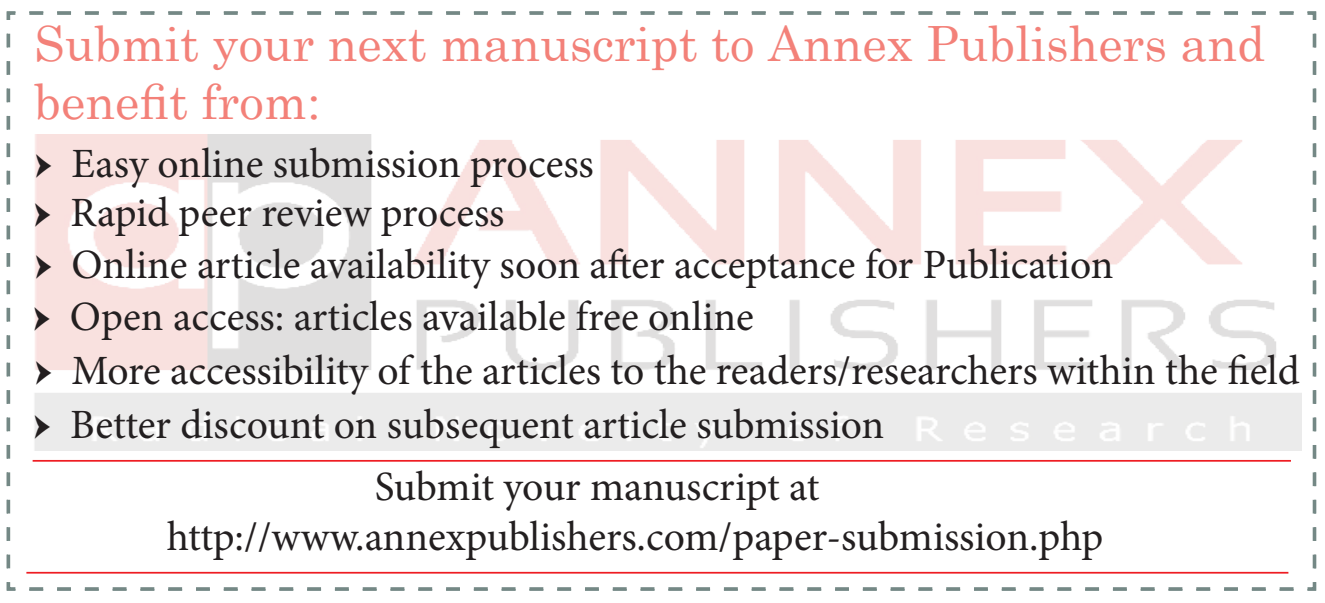

